\title{
Logistics Planning and Visualization of Modular Integrated Construction Projects Based on BIM-GIS Integration and Vehicle Routing Algorithm
}

\author{
Sanyuan $\mathrm{Niu}^{1}$, Yi Yang ${ }^{2}$, and Wei Pan ${ }^{3 *}$ \\ ${ }^{1}$ Post-Doctoral Fellow, Department of Civil Engineering, The University of Hong Kong \\ ${ }^{2}$ PhD candidate, Department of Civil Engineering, The University of Hong Kong \\ ${ }^{3}$ Associate Professor, Department of Civil Engineering, The University of Hong Kong \\ "Corresponding author's e-mail: wpan@ $h k u . h k$
}

\begin{abstract}
Logistics planning is a critical part of developing supply chain for modular integrated construction $(\mathrm{MiC})$ projects in Hong Kong where high-rise, high density and hilly landscape is the norm. It is important to minimize the total logistics and to guarantee timely delivery of modules, especially for several $\mathrm{MiC}$ projects being constructed during the same period. Nevertheless, there is a significant lack of studies on logistics planning, optimization and visualization for $\mathrm{MiC}$ projects. The aim of this paper is to establish an integrated $\mathrm{MiC}$ logistics planning and visualization platform, which is grounded on the integration of building information modeling (BIM), geographical information system (GIS) and vehicle routing problem (VRP) algorithm. The framework is then presented and evaluated using a case study to identify optimal logistics scenario of trailer routes to meet the installation time window of MiC projects in Hong Kong. The paper finds that the proposed platform has the ability to make optimized logistics scenario for MiC projects, and to visualize the logistics scenario in a 3dimentional interactive environment. Future study will focus on adopting flexible control strategies and including more decision-making criteria of logistics planning in $\mathrm{MiC}$ projects such as road width limitation, travel speed and different module types.
\end{abstract}

\section{KEYWORDS}

Modular integrated construction; Logistics planning; Building information modeling; Geographical information system; Vehicle routing problem

\section{INTRODUCTION}

Logistics plays a vital role in the development of MiC supply chains. However, the use of MiC raises some new or different requirements for logistics arrangements from those for traditional construction (Pan and Hon, 2018; Pan et al., 2018a,b). A questionnaire survey administered to 41 construction organisations in Singapore conducted by Hwang et al. (2018) revealed that three significant logistics constraints, namely, (1) increased transportation and logistics considerations, (2) limitations to design due to transportation restrictions (e.g. modules' dimensions), and (3) transport at restrictions due to rules and regulations, were ranked the 3rd, 6th, and 8th 
respectively among all the 18 widely-concerned constraints identified in prefabricated prefinished volumetric construction (PPVC) projects in Singapore.

In the context of Hong Kong, the supply chains of prefabrication have been established for years. However, as many uncertainties associated with logistics resource, workforce and process management have not been sufficiently addressed, the reliability of and efficiency in delivering prefabricated components is not very satisfactory. Zhai et al. (2015) proposed three strategies for enhancing the reliability of logistics performance and mitigating the uncertainties in the logistics, which are to reduce the length or variability of lead time, to set up buffer spaces in-between the factory and the site, and to adopt both. As Hong Kong is bracing the paradigm shift towards $\mathrm{MiC}$, an integrated logistics planning and visualization platform is required.

Following the introduction, the paper first reviews the literature of $\mathrm{MiC}$ logistics and innovative logistics planning technologies. Second, the MiC logistics planning and visualization framework is introduced. Next, the framework is presented using a case study of logistics planning in Hong Kong. Then, the feasibility of achieving just-in-time (JIT) delivery and the future development of the platform are discussed. The paper finally draws its conclusions.

\section{LITERATURE REVIEW}

\section{Logistics planning of MiC projects}

There are fundamental differences between traditional and $\mathrm{MiC}$ in terms of material delivery, coordination, temporary storage and inventory. For example, the modular components are typically large and cumbersome, necessitating extra caution when they are carried across public roads (Pan et al., 2018b; Azhar et al., 2013). The adoption of modular construction methods introduces an additional layer of complexity to logistics planning, given the interplay of manufacturing, transportation and assembly processes (Pan et al., 2018a).

Liu (2016) summarized that the logistics service in modular construction is featured by three features: specialization, high risks and time-driven. Ensuring the JIT delivery of modules to site is essential but still challenging to achieve in many cases (Liu, 2016). Some scholars argued that planning off-site transport of materials requires a systematic approach to accounting for material characteristics and the effects of delays in material delivery on the duration and costs of projects (Ahmadian et al., 2015). However, there is a lack of understanding of the planning and control of the transportation phase in modular construction, as supply chain management principles seem to be "neither wide-spread nor wholly adopted" in construction (Tennant and Fernie, 2014).

Researchers have proposed various strategies for ensuring the desired logistics performance in terms of module supply. For example, at the early stage of modular building projects, the project team will need a plan for material flow from the factory to the designated site and a mechanism to streamline and manage the process. To optimize the intermodal transportation performance, the coordination among all the involved parties should be improved (Makarova et al., 2017). To ensure a smooth installation workflow within the timeframe, a staging area close to the site can help to avoid module delivery delay and to address the limited site storage area for modules. However, preparing such facility appears to be a challenge to modular projects in congested cities (Javanifard et al., 2013). 


\section{Smart Logistics planning technologies for MiC: GIS, BIM and VRP}

GIS is a collection of computer hardware, software, and geographic data for capturing, managing, analyzing, and displaying all forms of geographically referenced information (Sarkar, 2007). Researchers applied GIS in conjunction with operational research techniques to solve problems such as vehicle routing (Campbell et al., 2001), time-critical logistics (Miller, et al., 1999), site location (Li et al., 2005) and warehouse management (Johnston et al., 1999). Researchers also adopted GIS to solve problems encountered in the construction process, e.g. exploiting health and safety information (Manase et al, 2011). The adoption of BIM in construction logistics provides stakeholders with improved clarity in the comprehension of logistics process using well-defined and easily understood information (Whitloc et al., 2018). For example, Cheng and Kumar (2015) presented a framework based on BIM for automated logistics planning and management, in which the geometric, schedule and material information were extracted from BIM models, and was integrated with a dynamic construction site layout model. In modular construction, it was revealed that BIM has good potential in facilitating the modular buildings' automated drafting and design (Alwisy et al., 2012), installation and construction (Ramaji et al, 2018). Nevertheless, the utilization of BIM in the logistics stage of modular building projects has been largely overlooked due to the lack of geographical and spatial data in BIM models. The integrated of BIM and GIS is thus critical in digitalizing the logistics process for stakeholders' decision-making.

The VRP refers to the problem of identifying an optimal set of routes for a fleet of vehicles to traverse in order to serve a given set of customers. The VRP is NP-hard, which makes it difficult to be solved by combinational optimization approaches. The two most widely studied extensions of the VRP are: (1) the capacitated VRP, where vehicles have load capacities, and (2) the VRP with time windows, which extends the capacitated VRP by adding time window constraints to depots and the customers on the route. MiC logistics planning is indeed a special type of VRP because: (1) there are time windows for module installation determined by the construction schedule on site, (2) each trailer can only take one or two modules in each travel, and (3) trailers should travel between sites and storage yards. There are many algorithms developed for solving the VRP, e.g. the artificial bee colony (ABC) algorithm proposed by Karaboga (2005), which was first applied to the VRP by Szeto et al. (2011).

\section{RESEARCH METHODS}

\section{Problem definition: logistics planning for MiC projects in Hong Kong}

According to the Planning Department (2016), in the short run, there are 11 potential areas for industrial sites in Hong Kong. It is assumed that the prospective local factories and storage yards for MiC pre-fabrication and pre-finishing tasks will be located in these areas. On the demand side, major committed/under planning land supply of Hong Kong includes 18 major areas, in which future MiC projects in Hong Kong are likely to be developed (Figure 1). Hong Kong has a road network that is among the most heavily used in the world. By September 2017, there were about 2,107 km of roads: $442 \mathrm{~km}$ on Hong Kong Island, $472 \mathrm{~km}$ in Kowloon and 1,193 km in the New Territories. The complex road networks and the dense development impose a constant challenge to the logistics planners. 


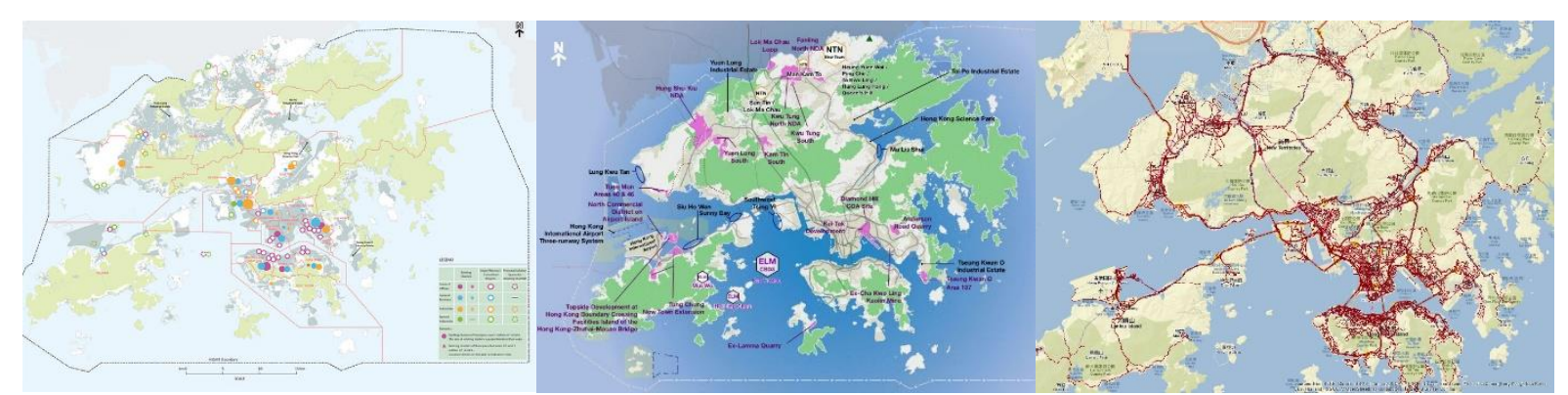

Figure 1. Prospective spaces for MiC storage, MiC project sites and road network in Hong Kong

In this study, it was assumed that there are $3 \mathrm{MiC}$ storage yards for modules in the potential sites for industrial use purposes, and $13 \mathrm{MiC}$ projects respectively in the major land supply areas. The depot for vehicle parking was also assumed to be located in one of the storage yards, and had 3 trailers to transport modules. The $13 \mathrm{MiC}$ projects have different installation schedules (time windows) of modules, and the optimization objective is to achieve the minimum total distance without compromising the time windows of the module installation tasks on site.

\section{The process of BIM-GIS integration}

The integration of BIM and GIS models was grounded on model conversion between different file types. In this study, Autodesk Revit was used as the BIM tool, and ESRI ArcGIS was used as the GIS platform. The BIM models of the 13 projects were first established. The modules were defined as independent libraries, and were linked to the cast-in situ parts of the model. COLLADA file format was selected as the medium for data transfer between BIM and GIS. Specific color code was adopted for visualizing the installation status of the modules, i.e., green for installed modules, red for modules being transported, and white for modules to be transported (Figure 2).

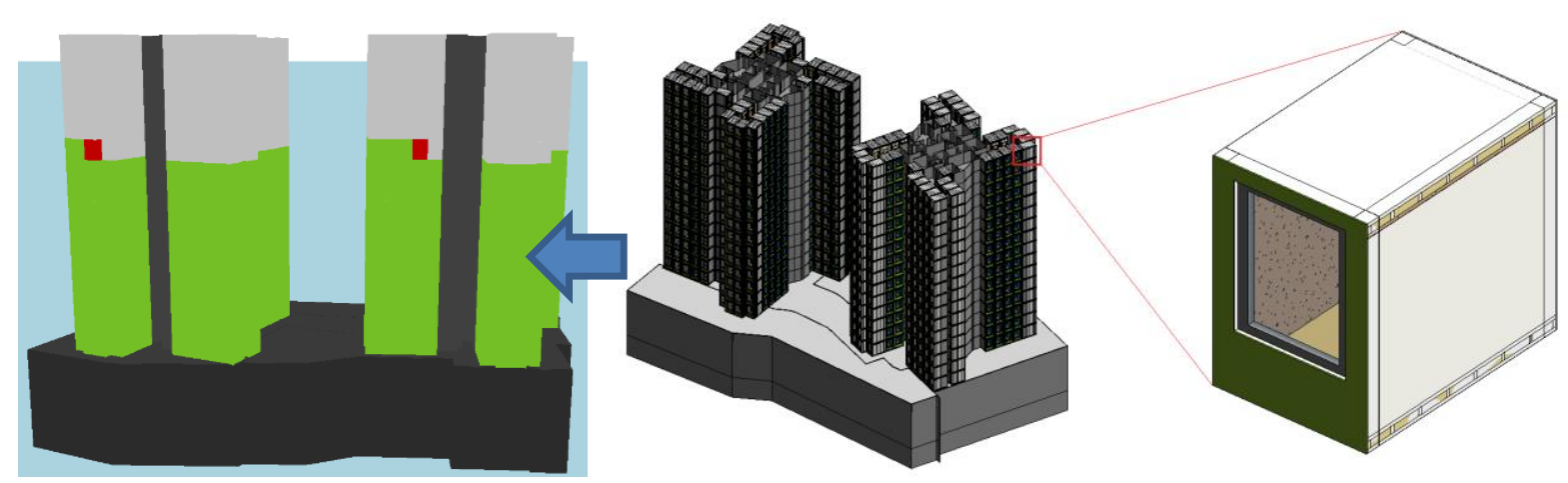

Figure 2. BIM-GIS integration of the planned MiC projects

\section{VRP algorithm adoption}

The VRP in this study was formulated on a complete directed graph formed by a set of nodes and a set of arcs.

- The node set is the union of a trailer depot, a set of MiC sites and a set of module storage yards. The trailer depot is also located in one of the storage yards.

- Let $V=\{0,1,2, \ldots, N+1\}$ be the set of nodes. Nodes 0 and $N+1$ denote the same depot, and every trailer route starts at 0 and terminates at $N+1$. 
- The set of arcs in the graph is denoted as $A=\{(i, j) \mid i, j \in \mathrm{V}, i \neq j\}$. Each $\operatorname{arc}(i, j)$ is associated with a distance $d_{i j}$ and a travel time $t_{i j}$. A binary variable $x_{i j}$ is used to denote whether a vehicle visits node $j$ after visiting node $i$. The variable $x_{i j}$ equals 1 if the vehicle uses the $\operatorname{arc}(i, j)$ and equals 0 otherwise.

- The maximum load capacity of a vehicle is denoted by $Q$, and $q_{i}$ represents the current load of a vehicle at node $i \in \mathrm{V}$. For MiC logistics, it is reasonable to assume $Q=q_{i}=1$ as each trailer can usually take only one module each time. Each node is also associated with a demand $p_{i}$. For site nodes, $p_{i}=1$, and for depot and storage yard nodes $p_{i}=0$.

- Each vertex $i \in V$ is characterized by a service time $s v_{i}$ and a time window $\left[r_{i}, l_{i}\right]$ in which the service (e.g. lifting using tower crane) is required to be provided. The service cannot start before the ready time $r_{i}$, i.e., if a trailer arrives earlier than $r_{i}$, it must wait. Also, the service cannot start after the latest time $l_{i}$, but can finish later than that time. The actual start time of service is denoted by variable $\tau_{i}$.

In this paper, the ABC algorithm proposed by Szeto et al. (2011) was adopted to solve the above VRP, as shown in Figure 3.

Steps of $A B C$ algorithm

- Generate initial solution set (food sources)

- Evaluate the solution set

- Set cycle to 1

- Repeat

- Find the neighbor solution

- Calculate the fitness value (nectar quantity)

- Apply the greedy selection process

- Choose a solution from the solution set

- Find the neighbor solution

- Calculate the fitness value

- Check whether replace: Yes, I_i=0; No, I_i=I_i+1.

(food source $\mathrm{x}$ i)

- If I_i=limit, abandon the solution. Replace it with a

new neighbor solution

- Memorize the best solution so far

- Cycle $=$ cycle +1

- Until cycle = Maximum iteration

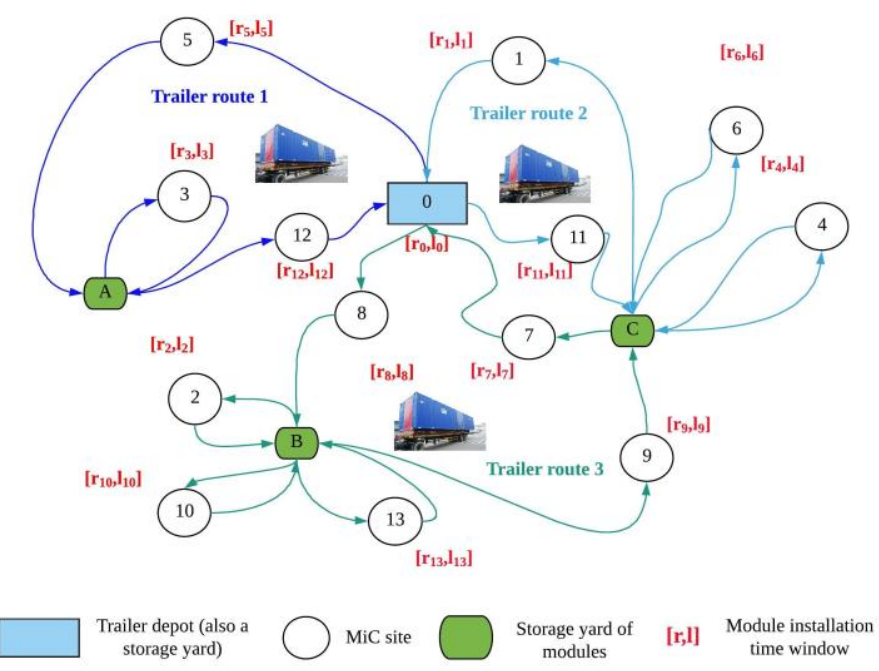

Figure 3. Steps of $\mathrm{ABC}$ algorithm (left) and solution example (right)

\section{RESULTS AND ANALYSES}

The integrated logistics planning and visualization platform was realized using ERSI ArcGIS online services. The platform consists of four layers: (1) city 3D model layer for visualizing the city landscape and the built environment, (2) project 3D layer for visualizing the modular buildings and the installation status of modules, (3) road network layer for visualizing the road network, and (4) logistics route layer for visualizing the optimized traveling route of trailers to transport modules from storage yards to sites (Figure 4). The optimal logistics scenario consists of three routes, each of which is served by a trailer respectively. In each route, a trailer loads modules from a storage yard and serves a number of construction sites in a specific order. The optimal logistics scenario is highlighted using specific color codes, and the sequence of trailer visit is indicated using marker symbols in the logistics route layer. 

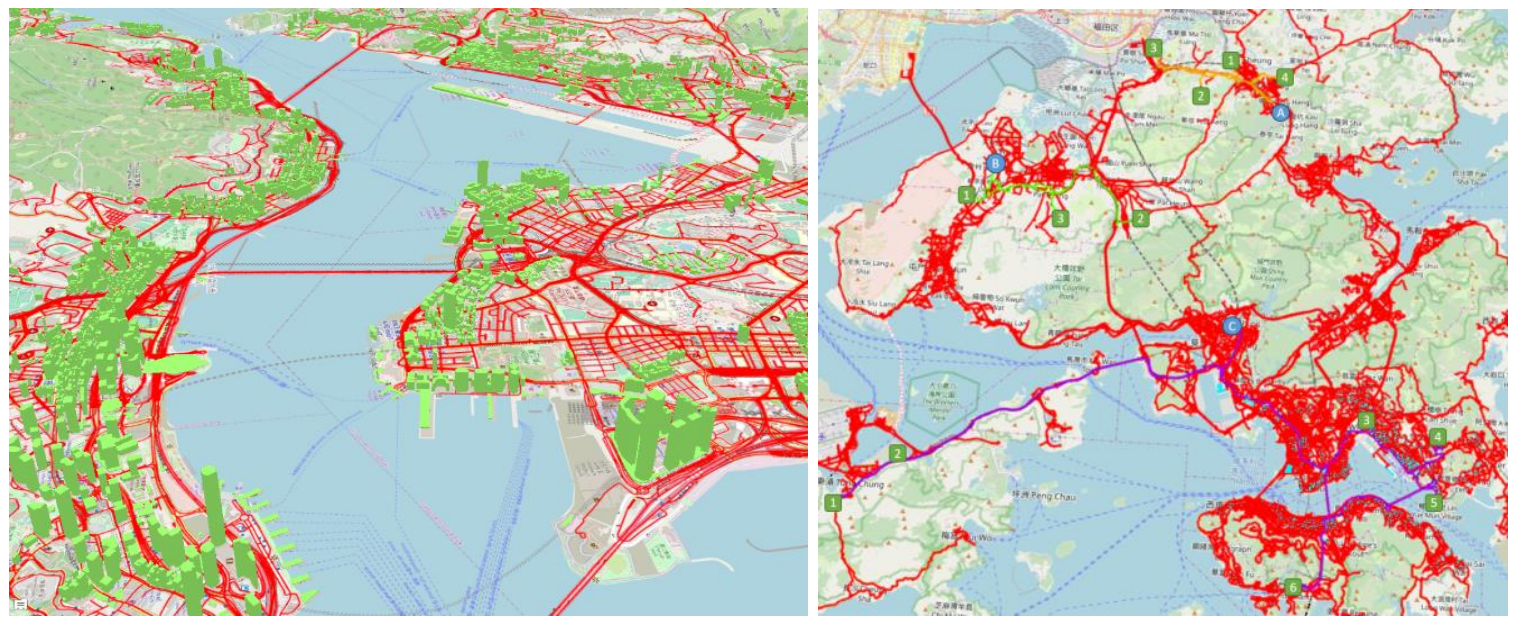

Figure 4. Integrated logistics planning and visualization platform and the optimized scenario

\section{DISCUSSION}

\section{Achieving JIT in MiC logistics: demand-driven or supply-driven?}

The construction logistics in Hong Kong is challenged by the fact that the sites usually have limited storage areas, and the achievement of JIT in logistics is necessary. In this study, the trailers' routes are optimised based on pre-settled time windows according to the installation schedule on site, i.e. the logistics planning is demand-driven. Nevertheless, it is reluctant to achieve JIT in module delivery merely through demand-driven approaches. The reasons are multi-fold: (1) the conflict between pre-determined times windows of concurrent MiC projects may result in zero feasible solutions; (2) the many uncertainties in the logistics process, e.g. traffic congestion can make the simulated logistics plan invalid, and (3) the typical floor cycle of the projects may increase as the project proceeds because the project team is more and more familiar with the entire process. In actual modular building projects, the logistics planning is usually supply-driven, and the tower crane should be prepared before the modules arrive. Successful implementation of JIT depends on the suppliers' flexibility, users' stability, total management and employee commitment as well as teamwork (Ali and Beheiry, 2015). More integrated and flexible planning strategies are thus required to coordinate both the demand and supply sides, e.g. model predictive control strategy (Perea-López et al., 2003).

\section{Towards multi-criteria MiC logistics planning}

Logistics planning for $\mathrm{MiC}$ project is a complex issue and requires multi-criteria decisionmaking. In this study, only the installation time window of modules is considered as a constraint, and the total travel distance is the only performance indicator for evaluating the performance of the route scenario. Nevertheless, the actual circumstance is much more complicated, and many other criteria should be included in the optimization model. For example, there should be many types of modules required in a single project, and the modules could be stored in different storage yards. A trailer may also visit a specific site multiple times as there are several modules to be installed in a single day. The restrictions in road transport, such as limits in lane width, height and maximum turning radius, would shape the trailer route according to the modules' dimensions. The objective function of the optimization algorithm should further include the number of trailers and the total cost because logistics suppliers have specific charging strategies. 


\section{CONCLUSION}

Logistics planning plays a vital role in the establishment of supply chain for modular integrated construction $(\mathrm{MiC})$. This paper presents an integrated platform for planning, optimizing and visualizing MiC logistics based on the integration of BIM and GIS and the adoption of VRP algorithm. Following pre-determined installation schedule of modules in BIM, the logistics scenario of transporting modules are optimized and visualized in an interactive 3D city-wide GIS environment. The optimized visiting routes of trailers to sites were calculated and highlighted, and the best storage yards for loading modules were also identified. Future study will focus on adopting flexible control strategies to achieve JIT in MiC logistics planning, and including more decision-making criteria such as different module types, multi-visit to sites and road constraints.

\section{REFERENCES}

Ahmadian, F.A., Akbarnezhad, A., Rashidi, T.H., and Waller, S.T. (2015). "Accounting for transport times in planning off-site shipment of construction materials." Journal of Construction Engineering and Management, 142(1), 04015050.

Alwisy, A., Al-Hussein, M., and Al-Jibouri, S. (2012). "BIM approach for automated drafting and design for modular construction manufacturing." Congress on Computing in Civil Engineering, Proceedings. 10.1061/9780784412343.0028.

Azhar, S., Lukkad, M.Y., and Ahmad, I. (2013). "An investigation of critical factors and constraints for selecting modular construction over conventional stick-built technique." International Journal of Construction Education and Research, 9(3), 203-225.

Campbell, J.F., Labelle, A., and Langevin, A. (2001). "A hybrid travel distance approximation for a GIS-based decision support system." Journal of Business Logistics, 22(2), 165-182.

Cheng, J., and Kumar, S. (2015). "A BIM-based framework for material logistics planning." The 23rd Annual Conference of the International Group for Lean Construction (IGLC), At Perth, Australia.

Gibb, A.G. (1999). Off-Site Fabrication: Prefabrication, Pre-Assembly and Modularisation, John Wiley \& Sons.

Hsu, P.Y., Angeloudis, P. and Aurisicchio, M. (2018). "Optimal logistics planning for modular construction using two-stage stochastic programming." Automation in Construction, 94, 47-61.

Hwang, B.G., Shan, M., and Looi, K.Y. (2018). "Key constraints and mitigation strategies for prefabricated prefinished volumetric construction." Journal of Cleaner Production, 183, 183-193.

Javanifard, N., Markert, D., Strobel, K., and Yap, J. (2013). Modular Prefabricated Residential Construction: Constraints And Opportunities. Pacific Northwest Center for Construction Research and Education, Seattle.

Johnston, D.A., Taylor, G. D., and Visweswaramurthy, G. (1999). "Highly constrained multifacility warehouse management system using a GIS platform." Integrated Manufacturing Systems, 10(4), 221-233.

Karaboga, D. (2005). An idea based on honey bee swarm for numerical optimization. Technical report-TR06, Computer Engineering Department, Erciyes University.

Lawson, M., Ogden, R., and Goodier, C. (2014). Design in Modular Construction, CRC Press.

Li, H., Yu, L., and Cheng, E. (2005). "A GIS-based site selection system for real estate projects." Construction Innovation: Information, Process, Management, 5(4), 231-241. 
Liu, J. (2016). The Significance of Logistics Performance to Industrial Modular Construction Project under the "Big Site" Scenario. University of Alberta.

Makarova, I., Shubenkova, K., and Pashkevich, A. (2017). "Logistical costs minimization for delivery of shot lots by using logistical information systems." Procedia Engineering, 178, 330-339.

Manase, D., Heesom, D., Oloke, D., Proverbs, D., Young, C., and Luckhurst, D. (2011). “A GIS analytical approach for exploiting construction health and safety information." Journal of Information Technology in Construction, 16. 335-356.

Miller, H., Wu, Y., and Hung, M. (1999). "A GIS-based dynamic traffic congestion modelling to support time-critical logistics." In Proceedings of the Hawaii International Conference on System Science, Maui, Hawaii.

Mohamed A., and Salwa, B. (2015). "The applicability of just-in-time in United Arab Emirates construction projects." Journal of Emerging Trends in Engineering and Applied Sciences. 6(2), 120-128.

Pan, W., and Hon, C.K. (2018). "Modular integrated construction for high-rise buildings." Proceedings of The Institute of Civil Engineers - Municipal Engineer.

Pan, W., Yang, Y., and Yang, L. (2018a). "High-rise modular building: ten-year journey and future development." Construction Research Congress, New Orleans, Louisiana, USA.

Pan, W., Yang, Y., Zhang, Z., Luo, Z., and Chan, S. (2018b) Modularisation for Modernisation: A Strategy Paper Rethinking Hong Kong Construction. The University of Hong Kong and Development Bureau of HKSAR Government, Hong Kong.

Perea-López, E., Ydstie, B.E., and Grossmann, I.E. (2003). "A model predictive control strategy for supply chain optimization." Computers \& Chemical Engineering, 27(8-9), 1201-1218.

Planning Department (2016). Hong Kong 2030+: Towards a Planning Vision and Strategy Transcending 2030. Planning Department, HKSAR.

Pryke, S. (2009). Construction Supply Chain Management: Concepts and Case Studies, Oxford, Wiley-Blackwell.

Ramaji, J.I., Memari, A., and Solnosky, R. (2014). "Integrated BIM platform for multi-story modular building industry." 2nd Residential Building Design \& Construction Conference.

Sarkar, A., (2007). GIS Applications in Logistics: A Literature Review. U.S. SBA Grant No. SBAHQ-06-1-004.

Szeto, W.Y., Wu, Y., and Ho, S.C. (2011). "An artificial bee colony algorithm for the capacited vehicle routing problem." European Journal of Operational Research, 215(1), 126-135.

Tennant, S., and Fernie, S. (2014). "Theory to practice: A typology of supply chain management in construction." International journal of construction management, 14, 56-66.

Whitlock, K., Abanda, H., Manjia, M., Pettang, C., and Nkeng, G.E. (2018). "BIM for Construction Site Logistics Management." Journal of Engineering, Project, and Production Management, 8. 47-55.

Zhai, Y., Zhong, R.Y., and Huang, G.Q. (2015). "Towards operational hedging for logistics uncertainty management in prefabrication construction." IFAC-PapersOnLine, 48, 11281133. 